\title{
CONDIÇÃO DE EXPORTAÇÃO E EMPREGO FORMAL NA INDÚSTRIA BRASILEIRA, 2003-2008*
}

\author{
Cassiano José Bezerra Marques Trovão ${ }^{a}$ \\ Claudio Salvadori Dedecca ${ }^{b}$
aEstudante do Doutorado em Desenvolvimento Econômico da
Universidade Estadual de Campinas (UNICAMP).

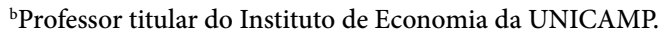

Artigo recebido em 19/02/2013 e aceito em 23/09/2014.

RESUMO: A recomposição da base produtiva brasileira, após a década 1990, ocorreu em um contexto de economia aberta e exposta à maior concorrência internacional, muitas vezes estabelecida em condições desfavoráveis, mas caracterizada por maior inserção externa da indústria brasileira. Este ensaio analisa os efeitos desse contexto econômico para a geração de empregos no setor industrial, segundo a condição de inserção das empresas no mercado internacional. Busca elucidar se a inserção externa das empresas está associada a perfis ocupacionais mais favoráveis em termos de qualificação e estabilidade do emprego. Os resultados confirmam que a continuidade da trajetória de crescimento com inserção externa representa um vetor relevante para maior qualificação da força de trabalho.

PALAVRAS-CHAVE: Emprego industrial; condição de exportação; mercado de trabalho formal.

\section{CLASSIFICAÇÃO JEL: J21; J4; L60.}




\section{EXPORT CONDITIONS AND FORMAL}

\section{EMPLOYMENT IN BRAZILIAN MANUFACTURING} INDUSTRIES IN THE PERIOD 2003-2008

ABSTRACT: The rearrangement of Brazil's production base took place after the 1990s, in a period of an open economy and greater international insertion of the Brazilian industry, on the one hand, and of greater exposure to international competition, often under unfavourable conditions, on the other. This study examines to which extent economic determinants affected job creation in manufacturing industries according to the degree of international insertion of the firms. It aims to determine whether the internationalization of Brazilian firms is associated to more favourable occupational profiles in terms of qualification and job stability. Results confirm that the continued growth trend associated with external insertion is a relevant propeller to a greater qualification of the workforce.

KEYWORDS: Industrial employment; export condition; formal labor market.

\section{INTRODUÇÃO}

Após 20 anos marcados pela ausência de perspectivas de crescimento sustentado, o Brasil presenciou uma retomada da possibilidade de crescimento na primeira década do século XXI. Essa expansão econômica ocorreu com características inéditas, expressas no contexto de baixa inflação, razoável controle das contas públicas e inserção nos mercados externos em um regime de economia aberta.

Ao contrário das perspectivas econômicas desfavoráveis que dominaram os anos 1980 e 1990, elas foram progressivamente se transformando durante a década de 2000 restabelecendo a possibilidade de crescimento sustentado a partir da articulação dos mercados interno e externo, mostrando capacidade de manter uma respeitável geração tanto de empregos formais quanto de renda. Uma visão otimista, que deve ser considerada exacerbada, substituiu o pessimismo que dominava a sociedade no início do período.

Mesmo considerando a situação econômica mais favorável, são ponderáveis os desafios que a sustentação do crescimento apresenta para a sociedade brasileira. Em grande medida, a expansão econômica recente baseou-se em um conjunto de capacidades existentes. É amplamente reconhecido que o país conta com uma taxa de investimento relativamente baixa, necessitando ampliar as capacidades produtiva, de infraestrutura, tecnológicas e humanas.

No que diz respeito à indústria de transformação, é fundamental que o investimento na ampliação da capacidade produtiva traduza-se em incorporação tecnológica e elevação da qualificação da força de trabalho visando elevar o valor adicionado e a produtividade setorial. Este resultado é necessário para modificar positivamente a estrutura industrial e sua inserção externa, propiciar um padrão salarial mais elevado e, em um curto e médio prazo, enfrentar a valorização da moeda nacional frente ao dólar

As novas condições que caracterizaram a economia brasileira na década de 2000 devem ser analisadas considerando dois momentos distintos.

Entre 2000 e 2004, após a crise externa de 1999, a desvalorização cambial, em um contexto de crescimento da economia internacional, estimulou a atividade produtiva, permitindo uma recuperação lenta da produção e do emprego, movimento constrangido pela situação de instabilidade econômica associada ao endividamento externo e interno. O setor exportador teve papel determinante na retomada da economia, permitindo pela primeira vez a recorrência de saldos comerciais positivos que possibilitaram tanto o equacionamento do endividamento externo, quanto a formação de reservas internacionais, que se tornaram expressivas ao final da década.

A partir de 2005, a retomada econômica foi fortalecida pela reativação do mercado interno, processo estimulado tanto pelo efeito da renda das exportações, quanto pelas 
políticas de salário mínimo, ampliação do crédito, aumento da renda associado ao incremento do emprego e pela retomada dos investimentos. Nesta fase, a contribuição do crescimento econômico para o aumento da receita fiscal, articulada a um maior controle dos gastos correntes, foi propiciando melhoria das contas públicas, movimento que acabou por abrir espaço para a retomada dos investimentos e das políticas públicas orientadas para a ampliação da infraestrutura, do consumo e da capacidade produtiva e, por consequência, do emprego.

Apesar do patamar mais relativamente baixo da taxa de crescimento observada, os efeitos em termos de renda per capita foram expressivos, resultado este associado ao incremento reduzido da população brasileira da ordem de $1,1 \%$ a.a. A renda per capita no segundo quinquênio da década de 2000 cresceu 3,3\% a.a., contra uma taxa 1,4\% a.a. no primeiro período. Para a região Nordeste, a renda per capita aumentou cerca de $4,5 \%$ a.a. na segunda metade da década.

A situação favorável do mercado interno e a resposta rápida do governo na ampliação do crédito, aliadas à manutenção do ciclo de preços das commodities no mercado internacional, permitiram atenuar os impactos da crise internacional de 2008-2009, bem como viabilizar a rápida retomada do crescimento econômico em $2010^{1}$.

A capacidade de enfrentamento da crise constituiu-se em um sinal importante da possibilidade de o país estabelecer uma trajetória de crescimento sustentado durante a década de 2010, cuja consolidação dependeria tanto da superação das dificuldades de expansão da economia internacional, especialmente dos EUA e Europa, quanto do enfrentamento das restrições internas relativas às capacidades produtiva, de infraestrutura, tecnológica e humana. Somam-se a estes desafios o problema cambial e o da taxa de juros, que tendem a afetar diretamente o investimento e a produção interna.

O equacionamento das restrições existentes é fundamental para viabilizar a possibilidade de a indústria e a agricultura aproveitarem os efeitos virtuosos e conjugados de um crescimento baseado nos mercados interno e externo, sem o comprometimento da oferta local em uma situação de aumento da renda e do consumo corrente da população. Ademais, a superação das restrições é decisiva para enfrentar, em médio e longo prazos, a tendência de valorização do Real, em especial no que se refere à provocada

\footnotetext{
1 É importante ressaltar que a possibilidade de resposta rápida do governo à crise contou, ao menos, com três condições favorívis não encontradas em contextos semelhantes ocorridos no passodo. A quase ausente dependência da importacão de petróleo, a existência de reservas externas reais e em volume mais sente depic mais expressivo, a balana comorich controle, a baixa inflação e o razoável controle das contas públicas foram algumas das condições que garantiram respostas rápidas ao enfrentamento da crise, orientadas para a sustentação da atividade econômica, em substituição ao padrão de medidas de natureza restritiva adotado pelos governos em situações semelhantes vividas pelo país no passado.
}

pelo ingresso de recursos externos, alimentado pelas perspectivas mais favoráveis de crescimento da economia brasileira comparativamente às existentes para as economias desenvolvidas, e pela estratégia cambial e de exportação da China, que cria condições de concorrência desfavorável para a produção brasileira² .

Pode-se afirmar que, ao contrário das expectativas prevalecentes nos anos $1980 \mathrm{e}$ 1990, o padrão de crescimento da década de 2000 mostrou-se dependente da dinâmica da indústria de transformação. Ao longo desse período, o setor mostrou capacidade de recuperação da produção e recomposição do seu tecido produtivo, ainda que restrita, bem como sua relevância em termos de geração de emprego e renda para o mercado de trabalho e a sociedade brasileira.

$\mathrm{Na}$ síntese de indicadores encontrada no Gráfico 1, nota-se uma relação estreita entre o comportamento do PIB e daquele do setor industrial desde o final dos anos 1990. As variações do PIB tenderam a ser simétricas às observadas para o PIB industrial, apesar de o desempenho setorial ter apresentado força relativamente menos acentuada.

Um aspecto importante a se destacar da recuperação recente da atividade econômica foi a recomposição ponderável do emprego formal, que se estabeleceu de modo importante no setor industrial e com espraiamento expressivo no território nacional. O resultado contrariou o prognóstico desfavorável presente na década de 1990 quanto à perda de capacidade de crescimento e de geração de emprego do setor industrial Entre 1999 e 2009, ele respondeu por quase 20\% da criação de empregos formais ocorrida no país, além de ter exercido papel decisivo na geração de divisas e na recuperação da taxa de investimento. Existe evidência, portanto, de que a possibilidade de manutenção do padrão de crescimento dos anos 2000 depende e dependerá da contribuição da indústria, exigindo que as restrições ao desenvolvimento setorial sejam removidas.

Uma questão central para a trajetória futura do setor industrial refere-se à evolução da sua estrutura ocupacional, reconhecidamente dominada por ocupações de menor qualificação e, em sua maioria, de baixa produtividade. A necessidade de adensamento tecnológico dos diversos segmentos industriais, tanto no processo de produção quanto nos bens, requer a elevação do perfil de qualificação da estrutura de ocupações do setor. Este movimento é fundamental, seja para o enfrentamento da concorrência externa, seja para a ampliação da inserção nos mercados internacionais

\footnotetext{
2 É provável que medidas administrativas de proteção contra a concorrência desleal (dumping) sejam necessárias e obrigatórias para enfrentar a estratégia chinesa. Contudo, a maior densidade tecnológica e produtividade mais elevada da base produtiva nacional constituem fatores decisivos para o crescimento de médio e longo prazo baseado no mercado interno e em uma melhor inserção nos mercados externos. Ver também Puga (2005 e 2006), FIESP (2006), Jayme et al. (2009) e Moreira et al. (2010).
} 
Gráfico 1 - Índices de produto e emprego formal no Brasil

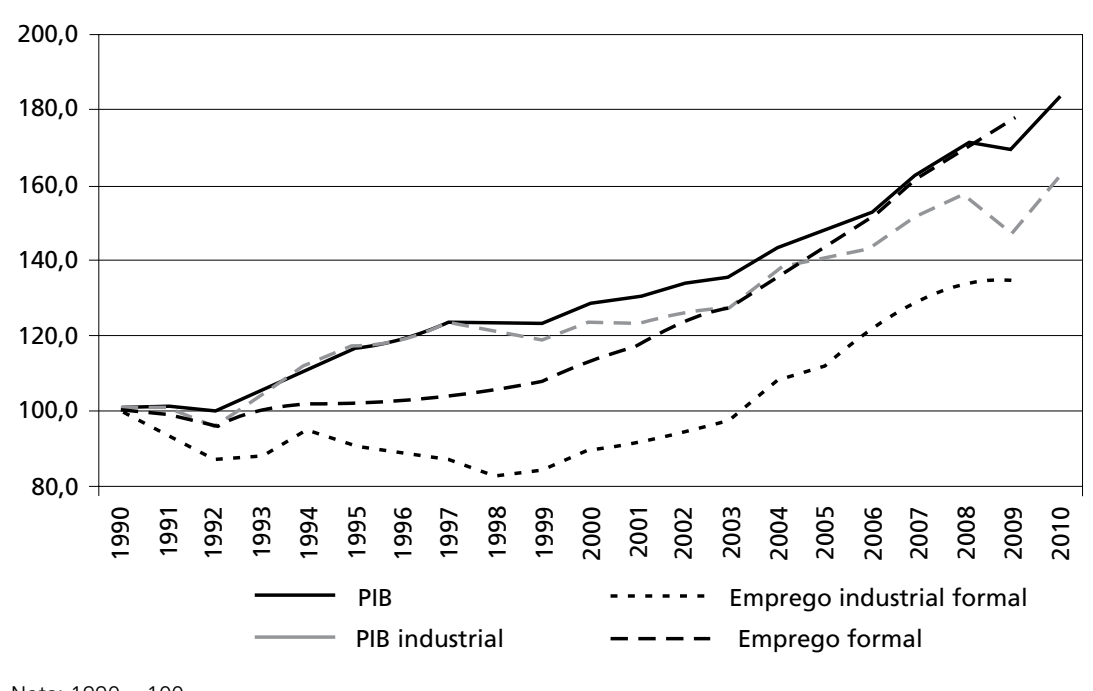

Fonte: Elaboração própria com base em dados de BACEN, IPEADATA e RAIS

O desempenho industrial dos anos 2000 foi marcado, pela primeira vez, por uma inserção mais sustentável nos mercados externos, que se traduziu na geração recorrente de superávits ${ }^{3}$. É provável que a inserção externa tenha induzido as empresas exportadoras a estabelecerem estratégias de produção, comerciais e tecnológicas, visando aproveitar as oportunidades existentes e que podem ter afetado suas estruturas ocupacionais. Também deve se reconhecer que, por serem exportadoras, elas podem associar vantagens produtivas que se traduzem em estruturas ocupacionais com perfil de qualificação mais favorável.

Portanto, cabe considerar a hipótese de que uma maior inserção internacional constitui um vetor relevante para a elevação do perfil de qualificação da estrutura ocupacional da indústria, o que deve se traduzir em maior produtividade, mas também em melhores salários e mesmo em maior estabilidade dos contratos de trabalho no setor.

Com o propósito de contribuir para este debate, foi explorado o período de 2003 a 2008, por representar um momento expressivo da geração de emprego formal da economia brasileira e por combinar reativação econômica com expansão acelerada das exportações. Ademais, esse período antecede a crise internacional do final de

3 Cabe ressaltar, mais uma vez, a menor e decrescente dependência da importação de petróleo conhecida pelo país, que foi decisiva para a geração do superávit, mesmo no momento de crise aguda de 2008-2009.
2008, que perdura e gera dificuldades para a economia mundial como um todo até o presente momento. $\mathrm{O}$ incremento da atividade econômica teve nas exportações um vetor de estímulo preponderante, em segundo plano, pela contribuição do mercado interno. Nesse sentido, pretende-se explorar as possíveis contribuições das exportações para a estrutura de emprego formal do segmento industrial das empresas com alguma inserção no mercado internacional, em contraposição com aquele segmento com inserção restrita ao mercado interno. A análise procura, portanto, explicitar as possíveis modificações e diferenças existentes entre as estruturas de emprego dos estabelecimentos exportadores e dos não exportadores, especialmente no que se refere ao perfil ocupacional em termos de qualificação, de salários e da estabilidade do contrato de trabalho.

Os resultados desse ensaio indicam que os estabelecimentos industriais exportadores perceberam uma ampliação do nível de emprego relativamente maior e que o perfil de sua estrutura de emprego mostrou-se relativamente mais favorável, em termos de indicadores de salário e de estabilidade do contrato de trabalho. Sugerem, também, que o crescimento das exportações pode alimentar um vetor indutor de elevação da qualidade do emprego do setor industrial dinamizado pelos estabelecimentos com inserção externa recorrente.

Em síntese, o ensaio tem o objetivo de analisar as principais características da evolução do emprego formal da indústria, segundo a condição de exportação dos estabelecimentos no período 2003-2008, que combinou crescimento econômico e expansão das exportações. A abordagem pretende evidenciar que a contribuição de uma maior inserção externa das empresas pode levar a um processo de qualificação da estrutura ocupacional da indústria de transformação no Brasil.

O estudo foi desenvolvido a partir de duas bases de dados: Relação Anual de Informações Sociais (RAIS/MTE) e Estatísticas de Comércio Exterior (DEPLA-SECEX/ MDIC). Em razão de alterações das classificações de ocupação e de atividade adotadas pela RAIS, a análise teve início no ano de 2003. Apesar do curto período abordado (2003-2008), os resultados permitem conhecer aspectos estruturais do perfil de emprego do setor industrial segundo condição de exportação e identificar possíveis mudanças que a maior inserção externa poderá sobre ele produzir.

O artigo está organizado em cinco seções e uma conclusão. Inicialmente, é apresentada a metodologia adotada para a análise da evolução da estrutura ocupacional, considerando a condição de exportação dos estabelecimentos ${ }^{4}$, a segmentação básica

${ }^{4}$ No ensaio, adota-se a definição de estabelecimento, mesmo considerando que na maioria das situações ela corresponda à de empresa. A referência para a definição da unidade produtiva foi o CNPJ, por ser 
adotada para a tabulação das informações e o desenvolvimento da análise. Em seguida, são apresentadas algumas informações básicas sobre as estruturas ocupacionais. $\mathrm{Na}$ terceira seção, são analisadas as alterações das estruturas ocupacionais. A quarta explora alguns indicadores de estabilidade do vínculo empregatício, e a última destina-se à abordagem das tendências dos níveis e diferenciais de salários.

\section{PERCURSO METODOLÓGICO}

A análise da evolução do emprego e do perfil ocupacional dos empregados dos estabelecimentos industriais brasileiros exigiu a elaboração de procedimentos metodológicos de duas naturezas. O primeiro buscou definir uma tipologia que permitisse identificar os estabelecimentos segundo sua condição de inserção no mercado internacional pela via das exportações. O segundo decorreu da escolha de um método econométrico que possibilitasse segmentar a estrutura ocupacional da indústria de acordo com os níveis de qualificação. Os passos dados para o desenvolvimento dos procedimentos metodológicos foram os descritos a seguir.

Em primeiro lugar, foram identificados os estabelecimentos industriais que exportaram durante todo o período ou parte dele. O procedimento realizou-se por meio da análise das informações sobre as estatísticas de importações e exportações industriais divulgadas regularmente pela Secretaria de Comércio Exterior (SECEX/MDIC). A análise da base de dados permitiu a identificação dos estabelecimentos exportadores para cada um dos anos considerados ${ }^{5}$. Foi construída uma base de dados dos estabelecimentos exportadores, tendo como identificador o número do Cadastro Nacional de Pessoa Jurídica (CNPJ).

Simultaneamente, foi elaborada outra base dos empregados dos estabelecimentos do setor industrial a partir da Relação Anual de Informações Sociais (RAIS), com identificação dos indivíduos segundo o PIS-PASEP e o CNPJ. A base continha infor-

esta a informação (chave) comum às bases de dados da SECEX e da RAIS. A maioria das empresas possui uma única inscrição, porém as grandes empresas possuem mais de uma. Não é possível fazer a depuração, isto é, a consolidação das inscrições das grandes empresas. Ao mesmo tempo, é possível identificar na base de dados da SECEX, que as grandes empresas tendem a utilizar um único CNPJ para realizar suas exportações. Portanto, acredita-se que o procedimento adotado não deve resultar em subestimativa relevante quanto às exportações das grandes empresas, apesar de este argumento não poder ser devidamente justificado em razão da não disponibilidade de dados adequados para o seu tratamento.

5 A definição dos exportadores deu-se apenas pela presença desses estabelecimentos que exportaram algum bem ou serviço nessa lista da SECEX. Portanto, não há ponderação pelo volume de exportação desses estabelecimentos, em decorrência da não disponibilidade de informação sobre os montantes. mações sobre ocupação, sexo, idade, escolaridade, tamanho do estabelecimento, unidade da federação e salário contratual.

As duas bases foram organizadas seguindo a estrutura e o padrão para uso no Statistical Package for the Social Sciences (SPPS) ou no Statistical Analysis System (SAS).

O passo metodológico seguinte foi o cruzamento das informações disponibilizadas pela SECEX com aquelas contidas na RAIS, isto é, a identificação dos estabelecimentos na base RAIS que segundo a SECEX exportaram em cada um dos anos do período de 2003 a $2008^{6}$. Como já mencionado, a adoção desses anos deveu-se, primeiro, à disponibilidade de informações sobre os estabelecimentos exportadores da SECEX, que se inicia em 2002. Em segundo, pela adoção, na RAIS, de uma nova versão da Classificação Brasileira de Ocupações (CBO) a partir de 2003. Finalmente, 2008 representa o último ano de crescimento acentuado que precedeu à eclosão da crise econômica e financeira internacional, que deprimiu a produção interna e afetou sobremaneira a atividade e o emprego industrial.

O terceiro passo realizado orientou-se para a definição da condição de exportação dos estabelecimentos. Três condições (tipos) foram adotadas para os estabelecimentos industriais: exportadores permanentes, exportadores potenciais e não exportadores.

Os estabelecimentos permanentes foram identificados por meio de um esforço de seleção, entre os anos de 2002 e 2008, dentre aqueles que apareceram tanto na RAIS quanto na SECEX, em todos os anos, sem exceção. Isso significa que foi criado um painel de estabelecimentos com exatamente o mesmo número de componentes em todos os anos. O objetivo da construção desse painel foi analisar o comportamento do emprego em estabelecimentos exportadores sistemáticos, controlando o efeito da entrada ou saída de novos estabelecimentos.

Este conjunto de estabelecimentos foi considerado como core do setor exportador industrial brasileiro, pois para que um estabelecimento assuma uma posição permanente ou consolidada frente ao comércio internacional devem existir fatores estratégicos que possibilitem a manutenção dessa condição.

De acordo com Veiga "há um amplo conjunto de fatores que podem exercer alguma influência sobre a decisão empresarial de exportar e crescer na exportação" (Veiga, 2002, p. 159). Entre esses fatores está o que o autor chamou de "a dimensão microeconômica do viés anti-exportador" (ibidem), que está relacionado à manutenção e à sustentação das exportações das empresas, pois isso requer uma grande mobi-

${ }^{6}$ Somente para aqueles estabelecimentos que aparecem na declaração da RAIS; quanto aos que não estão nessa relação não se pode fazer qualquer menção. 
lização de recursos organizacionais, financeiros e humanos, principalmente devido à inserção em diferentes mercados poder apresentar características e dinâmicas distintas do mercado interno e mesmo entre eles.

Além disso, há fatores ligados aos aspectos operacionais da atividade exportadora, como as dificuldades de adoção e condução das estratégias de exportação, e às operações de controle dos fluxos de comércio. Todos referem-se aos custos de transação relacionados à entrada na atividade exportadora e aos de operacionalização das vendas externas. Verificam-se, também, problemas relacionados aos gargalos em infraestrutura de transportes domésticos e internacionais, além de condições inapropriadas dos portos? . Para o autor, manter-se exportando por um longo período é "complicado, caro e arriscado, principalmente para quem tem acesso a um mercado doméstico de grande dimensão e ainda razoavelmente protegido" (Veiga, 2002, p. 161).

Foram considerados como estabelecimentos potenciais aqueles que exportaram em um ano ou mais, mas não o fizeram permanentemente. Eles foram assim chamados tendo em vista o entendimento de que exportar abre portas para que essas firmas adquiram experiência e ampliem a possibilidade de estabelecer uma condição mais permanente de inserção externa nos anos seguintes, mesmo reconhecendo as dificuldades e restrições que enfrentam para a consolidação da condição de exportadores sistemáticos.

Por fim, a classificação como não exportadores dá-se quase de forma automática e excludente. São estabelecimentos industriais que jamais apareceram na base de dados da SECEX, mas declararam pertencer ao setor industrial na RAIS.

Em poucas palavras, o procedimento metodológico de classificação dos estabelecimentos industriais desse estudo foi realizado segundo sua identificação na RAIS, tendo o conjunto sido segmentado em não exportadores e exportadores. Ressalte-se que esses últimos foram diferenciados entre potenciais e permanentes.

Esses passos permitiram a construção dessa tipologia de estabelecimentos industriais, foco para a análise do emprego formal do estudo. Após a definição metodoló-

\footnotetext{
7 Markwald e Puga (2002) fazem um estudo sobre alguns dos problemas enfrentados pelas empresas exportadoras e levantam algumas ações por parte do Estado que mereceriam atenção e auxiliariam as empresas na difícil tarefa de entrar no mercado internacional ou de permanecer nele como exportadora. Segundo os autores "[a] continuidade é condição necessária mas não suficiente, para garantir o sucesso do empreendimento exportador, pois, mesmo entre as exportadoras contínus (definidas como sucesso do emprente que exportaram de forma inite podem ser muito pronunciados. De fato, conforme constatado no estudo, a diversificação da linha de produtos, o up-grade tecnológico, a adaptação da oferta exportadora ao dinamismo do comércio mundial e a qualidade da gestão empresarial são atributos característicos das empresas mais dinâmicas" (Markwald e Puga, 2002, p. 149).
}

gica e a apresentação da tipologia referente à condição de exportação, parte-se para a definição e a agregação das ocupações dos empregados industriais com o objetivo de estudar a evolução do perfil do emprego nesse período a partir da identificação de tipos específicos ou grupos de ocupações que podem representar e caracterizar os empregados da indústria brasileira.

A construção dos grupos foi realizada a partir da técnica estatística de análise de agrupamentos (cluster analysis), que ordena os elementos (eventos) em grupos que possuam características semelhantes (Aldenfelder, 1984; Bailey, 1975).

Para a execução dessa técnica, devem ser explicitados os critérios (variáveis) que permitiram definir as semelhanças entre os elementos do estudo. Destaca-se que em grande parte das vezes essas variáveis necessitam de transformações para se tornarem comparáveis. É necessária, também, a escolha de um "coeficiente de similaridade" (aquele que garante a junção de elementos semelhantes) entre os objetos do estudo. Após isso, opta-se por um método de classificação desses grupamentos homogêneos. Tudo isso é necessário para que o objetivo final seja alcançado, ou seja, a avaliação e a interpretação dos resultados.

No que se refere à escolha das variáveis que definiram quão similares ou dissimilares eram os grupos, optou-se por aquelas que garantiriam de modo qualitativo uma classificação hierárquica de ocupações. O objetivo foi preservar certa homogeneidade interna aos grupos e uma diferenciação entre eles. Desse modo, foi possível criar uma escala de grupamentos ocupacionais, permitindo-se avaliar o comportamento do emprego segundo os critérios de hierarquização desses grupamentos.

As variáveis que definiram essa hierarquia foram: salário médio, salário mediano, massa de salários, anos de estudo e tempo de vínculo para os empregados formais em estabelecimentos industriais brasileiros. Estes dados permitiram que cada grupo fosse posicionado de acordo com o critério de qualificação dos postos de trabalho ${ }^{8}$.

O "coeficiente de similaridade" utilizado para se medir o quão similares, ou dissimilares, são os grupos foi a distância euclidiana ao quadrado, que é utilizada para atributos quantitativos, e que permite avaliar quão distante é um objeto do outro apontando sua diferenciação.

8 De acordo com Bussab et al. (1990, p. 13), "[u]m conceito fundamental na utilização das técnicas de A.A. (Análise de Agrupamento) "é a escolha de um critério que meça a distância entre dois objetos, ou que quantifique o quanto eles são parecidos. Esta medida será chamada de coeficiente de parecença. Cabe observar que tecnicamente pode-se dividir em duas categorias: medidas de similaridade e de dissimilaridade. Na primeira quanto menor o valor observado menos parecido (mais dissimilares) serão os objetos. Coeficiente de correlação é um exemplo de medida de similaridade, enquanto que distância euclidiana é um exemplo de dissimilaridade". 
A distância euclidiana (DE) entre dois elementos, $x$ e $y$, é a raiz quadrada do somatório do quadrado das diferenças entre os valores dos elementos. Esta é dada pela fórmula:

$$
D E(x, y)=\sqrt{\sum_{i}^{p}\left(x_{i}-y_{i}\right)^{2}}
$$

Uma variação dessa medida é a distância euclidiana ao quadrado (DEQ), medida escolhida como parâmetro para a medição das dissimilaridades entre os grupos e que é dada pela fórmula:

$$
\operatorname{DEQ}(x, y)=\sum_{i}^{p}\left(x_{i}-y_{i}\right)^{2}
$$

Para que as variáveis pudessem ser comparadas, eliminando-se, assim, os efeitos das diferenças de escala, sua padronização era condição indispensável. Esta padronização recebe o nome de " $z$-score", em que os valores são padronizados de modo que sua média seja zero e seu desvio padrão igual a um.

Após a definição do coeficiente de similaridade e da transformação das variáveis para que elas pudessem ser comparadas, fez-se necessária a definição do método de agrupamento. O escolhido foi o método de Ward ${ }^{9}$, que agrupa os elementos pela otimização da menor variância entre os grupos. Sua função de agregação é que define a hierarquia desses grupos.

Essa hierarquização é dada por uma função que determina a fusão de dois elementos pelo menor incremento na soma dos quadrados dos erros, isto é, um grupo, ou elemento junta-se a outro se o aumento na soma dos quadrados dos erros (SQE) for o menor possível. Por esse motivo, este é considerado um método de perda mínima de variância por agregação.

A função SQE é a soma dos quadrados dos desvios em relação a um valor médio ou ao valor de um centroide, que é a média de um vetor. Sua fórmula é expressa por:

$$
\operatorname{SQE}(X)=\sum_{i=1}^{n} x_{i}^{2}-\frac{1}{n}\left(\sum_{i=1}^{N} x_{i}\right)^{2}
$$

Em resumo, o objetivo do método de Ward é agregar os elementos estudados (nesse caso, as ocupações) em grupamentos, de tal forma que a variação em seu interior seja minimizada. Portanto, os grupamentos são fundidos de maneira que se reduza a varia-

\footnotetext{
9 Ver Ward (1963).
}

bilidade dentro de cada grupo. Para ser mais preciso, dois elementos são agrupados se esta fusão traduzir-se em um aumento marginal na soma dos erros ao quadrado.

A diferença entre cada caso dentro de um grupamento e a similaridade média são calculadas e elevadas ao quadrado (como no cálculo de um desvio-padrão). Por fim, a soma dos quadrados dos desvios é usada como uma medida de erro dentro de cada grupamento. Um caso só entra em um grupo se o incremento no erro for mínimo.

A construção dos agrupamentos, elaborada a partir do procedimento proposto por Ward, e o processamento das informações, realizado por meio de software SSPS, permitiram produzir um dendrograma, que consiste em uma representação gráfica dos resultados apresentados de maneira hierárquica. Esse gráfico possui a forma de uma "árvore", em que cada passo da agregação é representado pela união de dois "ramos" dessa árvore e cada ramo representa um grupamento.

Após a análise do dendrograma, verificou-se a possibilidade de se estudar cinco grupamentos distintos, com relativa heterogeneidade entre os grupos e considerável homogeneidade em seu interior.

O primeiro grupamento da escala hierárquica, considerado como o mais bem posicionado, é definido pelas ocupações vinculadas a cargos de alta direção da indústria. Esse grupamento é aquele que apresenta as melhores condições em termos de perfil ocupacional, pois possui os melhores indicadores de renda, escolaridade e de estabilidade (tempo de vínculo) de todo o setor industrial.

O segundo define-se pela predominância de ocupações que exigem nível superior de escolaridade, além de diversos cargos de supervisão. Qualitativamente, esse grupo também representa empregados em ocupações de nível elevado de salários, escolaridade e estabilidade.

O terceiro diz respeito aos empregados do chão de fábrica, isto é, aqueles ligados à produção direta, tais como embaladores e alimentadores da produção, empregados de montagem de tubulações e estruturas metálicas, além dos empregados nos processos de usinagem. Ademais, escriturários, assistentes e auxiliares administrativos também aparecem nesse grupo com participação significativa, em torno de $15 \%$. O terceiro grupo está no centro da hierarquia e apresenta características intermediárias do ponto de vista ocupacional.

O quarto representa os empregados em ocupações de nível técnico, além de algumas profissões de secretariado e de relações humanas. Esse grupamento apresenta características de média-baixa classificação, em termos de rendimento, escolaridade e estabilidade.

Por fim, o quinto e último grupo, que representa mais da metade do total das ocupações e encontra-se na posição menos favorável, pode ser caracterizado pela predominância de pessoas ligadas a ocupações de trabalho manual, tais como trabalhadores 
de confecção de roupas e calçados, empregados manuais do agronegócio (agroindústria e de alimentos), além de operadores de máquinas e equipamentos pesados.

A definição dos grupamentos constituiu o último procedimento metodológico necessário para a análise da evolução da estrutura ocupacional da indústria, segundo a condição de exportação dos estabelecimentos.

\section{TENDÊNCIA GERAL DO EMPREGO SEGUNDO PERFIL OCUPACIONAL}

Os resultados agregados mostram tendência de crescimento do nível de emprego em todos os grupamentos da estrutura de emprego da indústria brasileira entre 2002 e 2008. No entanto, a recomposição do nível de emprego do setor foi marcada de maneira relativamente mais acentuada pela ampliação da participação dos segmentos intermediários, mais precisamente do $2^{\circ}$ e do $3^{\circ}$ grupos melhor posicionados na hierarquia ocupacional, caracterizados por ocupações com perfis mais favoráveis de renda, educação e estabilidade do contrato de trabalho ${ }^{10}$. Apesar desta alteração da estrutura de emprego, os dados revelam a estabilidade da participação do grupo de base $\left(5^{\circ}\right.$ grupamento), isto é, a reiteração de uma parcela elevada do emprego com características ocupacionais menos favoráveis.

Nos $2^{\circ}$ e $3^{\circ}$ grupos preponderam ocupações de nível superior e de nível técnico $\left(2^{\circ}\right.$ grupamento), além de embaladores e alimentadores de produção, trabalhadores da montagem de tubulações e estruturas metálicas, da usinagem de metais e compósitos, escriturários em geral, assistentes e auxiliares administrativos ( $3^{\circ}$ grupamento). Já no $5^{\circ}$ grupo encontram-se ocupações de trabalho manual, auxílio à administração e manutenção, tais como montadores de máquinas e aparelhos mecânicos; trabalhadores da administração, conservação e manutenção de edifícios; mecânicos de manutenção de máquinas e equipamentos industriais; além de motoristas.

Em outras palavras, pode-se afirmar que as alterações provocadas na estrutura de emprego da indústria pelo crescimento econômico não foram suficientes para romper com o perfil dominado por ocupações de menor nível de qualificação, educação e salário.

O detalhamento do aumento do nível de emprego mostra que das 15 ocupações que mais cresceram em termos de volume de emprego, 10 pertenciam à base da hierarquia ocupacional da indústria brasileira, ou melhor, ao $1^{\circ}$ grupo (Tabela 2 ).

${ }^{10}$ A hierarquização das ocupações dos estabelecimentos industriais foi explicitada na seção metodológica.
Tabela 1 - Crescimento e participação dos ocupados formais em estabelecimentos industriais, segundo grupamentos ocupacionais no Brasil (2002-2008)

\begin{tabular}{lrrrrrrr}
\hline & $\mathbf{2 0 0 2}$ & $\mathbf{2 0 0 3}$ & $\mathbf{2 0 0 4}$ & $\mathbf{2 0 0 5}$ & $\mathbf{2 0 0 6}$ & $\mathbf{2 0 0 7}$ & $\mathbf{2 0 0 8}$ \\
\hline \multicolumn{7}{c}{ Crescimento $(\mathbf{2 0 0 3}=\mathbf{1 0 0})$} \\
\hline $1^{\circ}$ & 78,7 & 100,0 & 96,7 & 101,1 & 113,6 & 115,3 & 122,1 \\
$2^{\circ}$ & 64,2 & 100,0 & 107,2 & 114,7 & 125,7 & 135,1 & 146,4 \\
$3^{\circ}$ & 76,8 & 100,0 & 111,3 & 116,0 & 126,2 & 137,5 & 145,1 \\
$4^{\circ}$ & 129,9 & 100,0 & 105,5 & 106,9 & 113,0 & 118,8 & 112,2 \\
$5^{\circ}$ & 103,9 & 100,0 & 111,0 & 114,8 & 122,8 & 130,9 & 135,5 \\
Total & 97,3 & 100,0 & 110,3 & 114,2 & 122,8 & 131,6 & 136,1 \\
\hline \multicolumn{7}{c}{ Participação(\%) } \\
\hline $1^{\circ}$ & 0,2 & 0,2 & 0,2 & 0,2 & 0,2 & 0,2 & 0,2 \\
$2^{\circ}$ & 2,0 & 3,1 & 3,0 & 3,1 & 3,1 & 3,1 & 3,3 \\
$3^{\circ}$ & 23,8 & 30,2 & 30,5 & 30,7 & 31,0 & 31,5 & 32,2 \\
$4^{\circ}$ & 14,8 & 11,1 & 10,6 & 10,4 & 10,2 & 10,0 & 9,1 \\
$5^{\circ}$ & 59,2 & 55,4 & 55,8 & 55,7 & 55,4 & 55,1 & 55,2 \\
Total & 100,0 & 100,0 & 100,0 & 100,0 & 100,0 & 100,0 & 100,0 \\
\hline \multicolumn{70}{c}{}
\end{tabular}

Nota: $2003=100$

Nota. $2003=100$.

Em síntese, dos mais de 2,1 milhões de novos postos de trabalho gerados no setor industrial brasileiro entre 2003 e 2008, 41,7\% eram dos três primeiros grupamentos, aqueles considerados os de melhor posição na escala hierárquica de ocupações. Somente o grupo intermediário ( $3^{\circ}$ grupamento) respondeu por $37 \%$ da geração de emprego. Apesar de conhecer uma redução de sua participação no total do emprego industrial, o $5^{\circ}$ grupo apresentou um aumento da sua dimensão absoluta em mais de 1,1 milhão de empregados, da ordem de $50 \%$ do total de novos empregos criados no período (Tabela 2).

Os resultados revelam, portanto, um processo de dinamização da indústria de transformação marcado por uma alteração lenta de sua estrutura de emprego, acompanhada de uma reiteração de uma base ocupacional de baixa qualificação. Mesmo considerando o curto período de análise, pode-se afirmar que possíveis alterações mais substanciais da estrutura ocupacional deverão requerer um padrão de crescimento que promova alterações nos coeficientes técnicos de produção, isto é, dependentes de blocos de investimentos que aumentem a densidade tecnológica do processo produtivo e dos bens produzidos, de modo a exigir uma estrutura ocupacional com um perfil de qualificação mais elevado ${ }^{11}$. 
Tabela 2 - Relação das 15 ocupações de maior crescimento do número de empregos, segundo participação no crescimento e posição na hierarquia ocupacional em estabelecimentos industriais no Brasil (2003-2008)

\begin{tabular}{lcc}
\hline \multicolumn{1}{c}{ Ocupações } & $\begin{array}{c}\text { Grupamento } \\
\text { ocupacional }\end{array}$ & $\begin{array}{c}\text { Participação } \\
\text { (em \%) }\end{array}$ \\
\hline Embaladores e alimentadores de produção & $3^{\circ}$ & 11,8 \\
\hline Trabalhadores da confecção de roupas & $5^{\circ}$ & 5,8 \\
\hline Trabalhadores da montagem de tubulações e estruturas metálicas & $3^{\circ}$ & 5,4 \\
\hline Trabalhadores artesanais na agroindústria e na indústria de alimentos & $5^{\circ}$ & 5,2 \\
\hline Escriturários em geral, agentes, assistentes e auxiliares administrativos & $3^{\circ}$ & 4,5 \\
\hline Trabalhadores agrícolas & $5^{\circ}$ & 4,3 \\
\hline Condutores de veículos e operadores de equipamentos de elevação & $5^{\circ}$ & 3,6 \\
\hline Trabalhadores dos serviços de hotelaria e alimentação & $5^{\circ}$ & 3,5 \\
\hline Trabalhadores de usinagem de metais e de compósitos & $3^{\circ}$ & 3,3 \\
\hline Escriturários de controle de materiais e de apoio à produção & $5^{\circ}$ & 3,1 \\
\hline Vendedores e demonstradores & $5^{\circ}$ & 3,0 \\
\hline Montadores de máquinas e aparelhos mecânicos & $5^{\circ}$ & 2,7 \\
\hline Técnicos de nível médio em operações industriais & $3^{\circ}$ & 2,7 \\
\hline Trabalhadores nos serviços de administração, conservação e manutenção de edifício & $5^{\circ}$ & 2,6 \\
\hline Mecânicos de manutenção de máquinas e equipamentos industriais, comerciais e & $5^{\circ}$ & 1,9 \\
residenciais & & \\
\hline
\end{tabular}

Fonte: Elaboração própria com base em dados da RAIS (2003-2008).

\section{O CRESCIMENTO E O PERFIL OCUPACIONAL DO EMPREGO INDUSTRIAL SEGUNDO} CONDIÇÃO DE EXPORTAÇÃO

Com a preocupação de melhor explicitar as implicações da condição de exportação das empresas para a estrutura de emprego da indústria, será dado realce aos grupos intermediários que vêm apresentando aumento da sua participação relativa, apesar da reiteração da importância do grupo com menor qualificação.

É possível afirmar que o aumento ou a diminuição da participação dos grupos intermediários representa, respectivamente, uma melhora ou uma piora do perfil da estrutura de emprego do setor industrial brasileiro entre 2003 e 2008, pois eles são constituídos por ocupações de melhor qualificação, comparativamente à média dos empregados industriais. Portanto, o incremento de sua participação sinaliza a possível ocorrência de uma alteração positiva da estrutura de emprego do setor, com prováveis impactos favoráveis em termo de produtividade da mão de obra.
De acordo com os resultados apresentados na Tabela 3, nota-se uma tendência de elevação da participação dos grupos intermediários que independe da condição de exportação dos estabelecimentos. Constata-se, prontamente, que a recuperação econômica favoreceu tanto a recomposição do emprego como seu perfil de qualificação, havendo a probabilidade da continuidade do processo produzir alterações mais significativas na estrutura de emprego do setor industrial.

No que se refere ao perfil ocupacional dos estabelecimentos segundo a sua condição de exportação, percebe-se que aqueles em posição consolidada frente ao comércio internacional aparecem em situação relativamente mais favorável. Isso confirma a ideia de que exportadores permanentes possuem, relativamente aos não exportadores, um perfil sócio-ocupacional melhor.

Tabela 3 - Participação e crescimento do número de ocupados formais com perfil intermediário* na hierarquia ocupacional em estabelecimentos industriais, segundo condição de exportação no Brasil (2003-2008)

\begin{tabular}{|c|c|c|c|c|c|c|c|}
\hline & & 2003 & 2004 & 2005 & 2006 & 2007 & 2008 \\
\hline & \multicolumn{7}{|c|}{ Participação (em \%) } \\
\hline \multirow{9}{*}{$\begin{array}{l}\text { Grupamentos } \\
\text { Intermediários }\end{array}$} & Permanentes & 40,4 & 40,8 & 41,1 & 41,7 & 42,2 & 43,1 \\
\hline & Potenciais & 36,8 & 38,0 & 37,0 & 37,7 & 38,7 & 40,0 \\
\hline & Não exportadores & 30,2 & 29,9 & 30,5 & 31,1 & 31,3 & 32,2 \\
\hline & Total & 33,3 & 33,4 & 33,7 & 34,2 & 34,7 & 35,5 \\
\hline & \multicolumn{7}{|c|}{ Crescimento $(2003=100)$} \\
\hline & Permanentes & 100,0 & 112,2 & 116,3 & 120,9 & 128,6 & 127,7 \\
\hline & Potenciais & 100,0 & 125,8 & 122,6 & 131,9 & 162,5 & 175,7 \\
\hline & Não exportadores & 100,0 & 106,5 & 113,9 & 127,0 & 134,6 & 145,1 \\
\hline & Total & 100,0 & 110,9 & 115,9 & 126,2 & 137,3 & 145,2 \\
\hline \multirow{10}{*}{$\begin{array}{l}\text { Total da } \\
\text { Indústria }\end{array}$} & \multicolumn{7}{|c|}{ Participação (em \%) } \\
\hline & Permanentes & 21,3 & 21,5 & 21,3 & 20,3 & 19,9 & 18,8 \\
\hline & Potenciais & 13,6 & 15,0 & 14,5 & 14,2 & 15,9 & 16,1 \\
\hline & Não exportadores & 65,1 & 63,6 & 64,2 & 65,5 & 64,1 & 65,1 \\
\hline & Total & 100,0 & 100,0 & 100,0 & 100,0 & 100,0 & 100,0 \\
\hline & \multicolumn{7}{|c|}{ Crescimento $(2003=100)$} \\
\hline & Permanentes & 100,0 & 111,0 & 114,1 & 116,9 & 122,9 & 119,7 \\
\hline & Potenciais & 100,0 & 121,8 & 122,1 & 129,0 & 154,7 & 161,6 \\
\hline & Não exportadores & 100,0 & 107,7 & 112,6 & 123,5 & 129,7 & 136,2 \\
\hline & Total & 100,0 & 110,3 & 114,2 & 122,8 & 131,6 & 136,1 \\
\hline
\end{tabular}

Notas: $2003=100 .\left(^{*}\right)$ Ocupaçōes intermediárias referem-se aos segundo e terceiro grupamentos ocupacionais. Fonte: Elaboraç̧ão própria com base em dados da RAIS (2003-2008)

Também, observa-se uma situação de maior proximidade dos estabelecimentos com potencial de exportação em relação aos estabelecimentos permanentes. Pode-se dizer que a inserção internacional, mesmo que ainda não estabilizada, tende estar 
associada a uma estrutura de emprego de melhor qualificação. Além disso, os resultados indicam que estes estabelecimentos foram aqueles que apresentaram os maiores ganhos de emprego no período, levando a um aumento de sua participação na estrutura total de emprego do setor industrial. Quanto à evolução do estoque de emprego em estabelecimentos potenciais, nota-se um incremento expressivo de empregados do terceiro grupamento ocupacional. Esse crescimento está associado tanto ao posicionamento desses setores frente ao comércio internacional quanto ao elevado incremento no número de estabelecimentos sob essa condição de exportação.

Em termos de expansão do emprego, a performance menos expressiva ocorreu para os estabelecimentos exportadores permanentes, levando em conta que eles tiveram uma queda da participação relativa no emprego total da indústria. Isto é, apesar de os estabelecimentos exportadores permanentes terem um perfil mais favorável de qualificação, eles não se constituíram no carro-chefe da recomposição do nível de emprego do setor.

\section{ROTATIVIDADE E PADRÃO DE CONTRATAÇÃO NA \\ INDÚSTRIA BRASILEIRA ENTRE 2003 E 2008}

Uma dimensão importante para se entender as possíveis implicações das mudanças no perfil ocupacional dos empregados da indústria brasileira do período de 2003 a 2008, é o nível e a evolução da rotatividade da mão de obra.

Com o propósito de avaliar o processo de contratação no setor industrial, foi elaborado o Indicador de Não Rotatividade (INR). Ele expressa a relação entre o total de empregados contratados com vínculo ativo no dia 31 de dezembro do ano de referência e o total de empregados contratados no mesmo ano. O indicador permite conhecer qual a intensidade de contratos de trabalho rompidos dos empregados que foram contratados no ano de referência e, portanto, a recorrência dos contratos de curta duração no total de postos de trabalho gerados pela indústria. Quanto mais elevado for o seu valor, maior é a parcela de contratados que mantiveram seu contrato no ano de referência e, portanto, menor a rotatividade.

O aumento da rotatividade do setor industrial brasileiro constituiu tendência geral para o período analisado. A evolução do indicador segundo os grupamentos ocupacionais e a condição de exportação dos estabelecimentos evidencia duas dimensões relevantes da recuperação do emprego industrial no período analisado.

A primeira revela uma tendência de queda do INR para os grupamentos ocupacionais considerados e para os estabelecimentos, independentemente da sua situação de inserção nos mercados externos. O resultado reitera as análises existentes sobre a tendência de elevação da rotatividade durante o processo de recomposição do nível de emprego, ou melhor, na fase inicial de recuperação da atividade econômica (Saboia et al., 1997; Saboia, 2001).

Entretanto, deve-se explicitar que uma situação mais favorável do indicador é encontrada dentre os estabelecimentos exportadores, tanto para ocupações de nível intermediário quanto para a base da hierarquia. $\mathrm{O}$ resultado global demonstra uma menor incidência de contratos de trabalho de curto prazo nesses estabelecimentos, devendo-se ressaltar que eles apresentam tamanhos mais elevados e, por este motivo, tendem a apresentar vantagens em termos de estabilidade da produção e também do nível de emprego. Mesmo considerando tal ressalva, o resultado sugere que a maior inserção externa pode ser fator indutor para uma maior estruturação das empresas, fato que tende a influenciar positivamente a estabilidade do contrato de trabalho.

Tabela 4 - Evolução do indicador de não rotatividade para trabalhadores formais da indústria, segundo principais grupamentos ocupacionais e condição de exportação no Brasil (2003-2008)

\begin{tabular}{llllllll}
\hline & & $\mathbf{2 0 0 3}$ & $\mathbf{2 0 0 4}$ & $\mathbf{2 0 0 5}$ & $\mathbf{2 0 0 6}$ & $\mathbf{2 0 0 7}$ & $\mathbf{2 0 0 8}$ \\
\hline \multirow{4}{*}{$3^{\circ}$} & Permanentes & 78,4 & 79,3 & 77,0 & 76,8 & 75,8 & 69,3 \\
grupamento & Potenciais & 74,6 & 74,4 & 72,2 & 73,8 & 72,2 & 66,4 \\
& Não exportadores & 69,7 & 69,6 & 68,2 & 69,4 & 68,2 & 63,3 \\
& Total & 72,1 & 72,3 & 70,4 & 71,3 & 70,2 & 64,8 \\
\hline \multirow{4}{*}{$5^{\circ}$} & Permanentes & 64,3 & 66,8 & 63,6 & 62,8 & 64,9 & 59,3 \\
grupamento & Potenciais & 64,5 & 62,6 & 60,8 & 60,5 & 60,9 & 54,6 \\
& Não exportadores & 63,5 & 65,0 & 62,9 & 63,7 & 62,6 & 59,1 \\
& Total & 63,7 & 64,9 & 62,7 & 63,1 & 62,7 & 58,5 \\
\hline \multirow{4}{*}{ Total da } & Permanentes & 70,5 & 72,4 & 69,6 & 69,1 & 70,1 & 64,4 \\
Indústria & Potenciais & 68,8 & 67,8 & 65,8 & 66,3 & 66,0 & 60,2 \\
& Não exportadores & 65,8 & 66,8 & 65,1 & 65,8 & 64,9 & 61,1 \\
& Total & 66,8 & 67,8 & 65,8 & 66,3 & 65,8 & 61,4 \\
\hline
\end{tabular}

Fonte: Elaboraçăo própria com base em dados da RAIS (2003-2008).

A segunda dimensão a ser ressaltada refere-se às diferenças existentes entre grupamentos ocupacionais qualitativamente opostos. O comportamento do indicador para o quinto grupamento ocupacional apresenta um indicador menos favorável, situação que independente da condição de exportação. Este resultado sinaliza que uma maior inserção externa pode estimular alterações em favor de uma elevação do perfil de qualificação da estrutura ocupacional, movimento importante para reduzir a intensidade da contratação de curta duração no aumento do emprego. 


\section{A EVOLUÇÃO DOS SALÁRIOS DOS EMPREGADOS NA} INDÚSTRIA BRASILEIRA ENTRE 2003 E 2008

Os rendimentos dos empregados da indústria não apresentaram as mesmas taxas de crescimento que o volume de emprego. O aumento real dos salários ficou abaixo daquele do estoque de empregados em todo o Brasil entre 2003 e 2008. Enquanto o emprego aumentou $36 \%$, os salários tiveram uma valorização real de $15 \%$.

Essa situação fica mais nítida quando se comparam os tipos de estabelecimentos, segundo sua condição de exportação. Os potenciais exportadores apresentaram um aumento do total de postos de trabalho da ordem de $70 \%$. Isso se deve ao fato de haver uma grande entrada de novos estabelecimentos sob essa condição. Apesar de apresentarem um elevado crescimento do emprego, os rendimentos de seus empregados tiveram um ganho de $11 \%$, isto é, quase sete vezes menor.

Os exportadores permanentes apresentaram comportamento distinto, com características mais favoráveis. A elevação dos salários destes estabelecimentos foi relativamente superior à encontrada para estabelecimentos potenciais. Os ganhos salariais dos estabelecimentos permanentes foram próximos ao incremento do crescimento do estoque de ocupados, devendo-se considerar que a geração de empregos deles foi menos expressiva.

O maior ganho em termos reais deu-se entre os empregados dos estabelecimentos não exportadores. Com um aumento de $36 \%$ no total do emprego e com $17 \%$ de ganhos reais para os salários, esses estabelecimentos foram aqueles que apresentaram, ainda que baixo, o melhor desempenho no sentido de alterar positivamente o perfil salarial do emprego formal da indústria brasileira.

A dinâmica de elevação dos rendimentos reais mostrou-se diferenciada para os grupamentos ocupacionais. Pode-se perceber que os empregados que apresentaram maiores taxas de crescimento dos salários foram aqueles em melhor posição na hierarquia ocupacional. Em média, os cargos de diretoria obtiveram ganhos reais em seus rendimentos de mais de $20 \%$, ficando acima da média do total da indústria.

O $3^{\circ}$ grupamento ocupacional, responsável por mais de 30\% do total do emprego gerado na indústria brasileira, apresentou a menor taxa de crescimento dos rendimentos reais. Para todos os tipos de estabelecimentos, os ganhos reais dos empregados desse grupamento ficaram abaixo da média da indústria.

Esse comportamento mais favorável aos empregados do topo da hierarquia somado ao baixo desempenho dos salários do grupamento de maior crescimento do emprego, $03^{\circ}$, reiteraram o perfil desigual entre os salários dos empregados industriais nesse período.

Se, por um lado, o crescimento do número de empregados em ocupações melhor posicionadas mostrou-se favorável para alterar positivamente a estrutura de emprego, constata-se, por outro, que os segmentos intermediários conheceram uma baixa valo-

rização real de seus níveis salariais. Os resultados sugerem uma alteração negativa dos diferenciais de salários da estrutura de emprego, independentemente da condição de exportação, havendo uma sinalização de melhor desempenho dos salários do topo da hierarquia para os estabelecimentos exportadores permanentes.

Tabela 5 - Evolução dos rendimentos médios reais dos ocupados formais em estabelecimentos industriais, segundo grupamentos ocupacionais e condição de

\begin{tabular}{|c|c|c|c|c|c|c|}
\hline & 2003 & 2004 & 2005 & 2006 & 2007 & 2008 \\
\hline \multicolumn{7}{|c|}{ Permanentes } \\
\hline $1^{\circ}$ & 100,0 & 106,3 & 114,5 & 110,4 & 122,5 & 119,9 \\
\hline $2^{\circ}$ & 100,0 & 105,5 & 107,2 & 109,5 & 111,0 & 111,2 \\
\hline $3^{\circ}$ & 100,0 & 103,5 & 106,7 & 108,5 & 107,9 & 112,0 \\
\hline $4^{\circ}$ & 100,0 & 107,3 & 109,1 & 111,3 & 112,9 & 118,3 \\
\hline $5^{\circ}$ & 100,0 & 104,7 & 105,8 & 109,5 & 111,9 & 115,4 \\
\hline Total & 100,0 & 104,3 & 106,8 & 110,0 & 110,9 & 115,4 \\
\hline \multicolumn{7}{|c|}{ Potenciais } \\
\hline $1^{\circ}$ & 100,0 & 103,0 & 105,6 & 112,0 & 115,0 & 112,6 \\
\hline $2^{\circ}$ & 100,0 & 118,1 & 108,7 & 108,5 & 108,4 & 108,5 \\
\hline $3^{\circ}$ & 100,0 & 107,0 & 102,1 & 101,9 & 102,5 & 102,1 \\
\hline $4^{\circ}$ & 100,0 & 105,7 & 105,5 & 111,8 & 111,0 & 115,0 \\
\hline $5^{\circ}$ & 100,0 & 107,5 & 104,5 & 114,8 & 116,9 & 121,7 \\
\hline Total & 100,0 & 108,2 & 103,0 & 107,3 & 108,9 & 111,2 \\
\hline \multicolumn{7}{|c|}{ Não exportadores } \\
\hline $1^{\circ}$ & 100,0 & 107,3 & 110,8 & 125,2 & 125,0 & 131,6 \\
\hline $2^{\circ}$ & 100,0 & 101,1 & 106,5 & 112,1 & 109,2 & 115,5 \\
\hline $3^{\circ}$ & 100,0 & 98,5 & 103,2 & 110,3 & 108,5 & 113,4 \\
\hline $4^{\circ}$ & 100,0 & 102,0 & 106,3 & 112,2 & 110,1 & 120,6 \\
\hline $5^{\circ}$ & 100,0 & 102,7 & 105,2 & 112,3 & 113,3 & 116,5 \\
\hline Total & 100,0 & 100,0 & 104,6 & 112,1 & 111,3 & 116,9 \\
\hline \multicolumn{7}{|c|}{ Total } \\
\hline $1^{\circ}$ & 100,0 & 106,8 & 111,2 & 117,2 & 121,0 & 122,3 \\
\hline $2^{\circ}$ & 100,0 & 105,8 & 107,1 & 110,8 & 109,5 & 113,0 \\
\hline $3^{\circ}$ & 100,0 & 102,3 & 104,4 & 108,1 & 107,3 & 110,5 \\
\hline $4^{\circ}$ & 100,0 & 104,8 & 107,1 & 111,6 & 111,5 & 119,7 \\
\hline $5^{\circ}$ & 100,0 & 104,2 & 105,4 & 111,5 & 113,2 & 116,0 \\
\hline Total & 100,0 & 103,2 & 105,3 & 110,4 & 110,8 & 114,9 \\
\hline
\end{tabular}


A evolução dos salários não parece ter sido influenciada pelo avanço do perfil educacional observado em todos os grupos ocupacionais. Os estabelecimentos exportadores permanentes apresentam menor incidência de empregados com ensino fundamental incompleto (cerca de $18 \%$ ), contra $24 \%$ nos estabelecimentos não exportadores. Ambos tiveram uma redução da participação de empregados com baixa educação, processo comum também aos estabelecimentos potenciais (Tabela 6).

Apesar da incidência diferenciada da baixa educação conforme a condição de exportação e da melhoria generalizada do perfil educacional dos estabelecimentos, não se observaram ganhos salariais maiores para os estabelecimentos exportadores ou para os segmentos intermediários da hierarquia ocupacional, que apresentam situação educacional relativamente mais favorável à base da estrutura ocupacional. De certo modo, os resultados indicam uma estabilidade significativa da estrutura de salários segundo a condição de exportação e os grupamentos ocupacionais (ver Tabela 7).

Como consequência, confirma-se a reprodução de uma elevada dispersão salarial entre o topo e a base da hierarquia ocupacional. Os cargos de diretoria possuem salários em média de nove a dez vezes maiores que os empregados de ocupações de baixa qualificação ${ }^{12}$.

O quadro de elevada desigualdade dos salários dos empregados industriais brasileiros acirra-se e evidencia-se pelo hiato existente entre os estabelecimentos em condições distintas de exportação. Isto é, além da alta diferenciação entre os grupamentos, percebe-se que as ocupações de mesmo perfil se diferenciam, em termos de rendimentos, de acordo com a forma de inserção do estabelecimento. Por exemplo, um empregado do quinto grupamento em um estabelecimento exportador permanente aufere rendimentos $40 \%$ superior que empregados de mesmo perfil em estabelecimentos não exportadores, diferença que não se alterou ao longo do período.

A situação desfavorável aos empregados da base da hierarquia não deu sinais de alteração. Mesmo em um momento favorável à atividade produtiva e ao emprego industrial, não parece que tenham se estabelecido mecanismos que pudessem reduzir a desigualdade da estrutura de salários. Sob qualquer condição de exportação e em qualquer nível ocupacional, os rendimentos médios dos empregados não alteraram sua relação com a média do total da indústria, implicando uma manutenção desse quadro. Esta interpretação ganha respaldo quando se analisa a alteração do grau de concentração da estrutura de salários da indústria, notando-se uma redução tênue do indicador para os dois principais segmentos: exportadores e não exportadores.

${ }^{12}$ É preciso lembrar que os dados referem-se ao salário contratual, não incluindo os bônus por produtividade ou desempenho.
Tabela 6 - Evolução da participação dos ocupados formais em estabelecimentos industriais segundo nível de escolaridade, grupamentos ocupacionais e condição de exportação no Brasil (2003-2008)

\begin{tabular}{|c|c|c|c|c|c|c|c|c|c|}
\hline \multirow[b]{2}{*}{ Nível } & \multirow[b]{2}{*}{ Escolaridade } & \multicolumn{4}{|c|}{2003} & \multicolumn{4}{|c|}{2008} \\
\hline & & Permanentes & Potenciais & $\begin{array}{c}\text { Não } \\
\text { exportadores }\end{array}$ & Total & Permanentes & Potenciais & $\begin{array}{c}\text { Não } \\
\text { exportadores }\end{array}$ & Total \\
\hline \multirow{5}{*}{$1^{\circ}$} & $\begin{array}{l}\text { Fundamental } \\
\text { incompleto }\end{array}$ & 2,1 & 2,0 & 5,3 & 3,9 & 1,8 & 1,3 & 2,9 & 2,4 \\
\hline & $\begin{array}{l}\text { Fundamental } \\
\text { completo }\end{array}$ & 2,7 & 3,2 & 8,8 & 6,3 & 2,3 & 1,8 & 6,3 & 4,7 \\
\hline & Médio completo & 15,0 & 17,6 & 23,1 & 20,1 & 12,1 & 14,2 & 24,5 & 20,0 \\
\hline & $\begin{array}{l}\text { Superior } \\
\text { completo }\end{array}$ & 80,2 & 77,3 & 62,7 & 69,6 & 83,8 & 82,7 & 66,4 & 72,9 \\
\hline & Total & 100,0 & 100,0 & 100,0 & 100,0 & 100,0 & 100,0 & 100,0 & 100,0 \\
\hline \multirow{5}{*}{$2^{\circ}$} & $\begin{array}{l}\text { Fundamental } \\
\text { incompleto }\end{array}$ & 9,6 & 9,6 & 15,9 & 13,7 & 5,0 & 5,1 & 9,4 & 7,9 \\
\hline & $\begin{array}{l}\text { Fundamental } \\
\text { completo }\end{array}$ & 12,2 & 11,9 & 17,4 & 15,5 & 8,6 & 8,8 & 14,2 & 12,3 \\
\hline & Médio completo & 32,9 & 30,6 & 31,0 & 31,4 & 40,4 & 41,9 & 40,5 & 40,7 \\
\hline & $\begin{array}{l}\text { Superior } \\
\text { completo }\end{array}$ & 45,3 & 47,9 & 35,6 & 39,4 & 45,9 & 44,2 & 35,9 & 39,1 \\
\hline & Total & 100,0 & 100,0 & 100,0 & 100,0 & 100,0 & 100,0 & 100,0 & 100,0 \\
\hline \multirow{5}{*}{$3^{\circ}$} & $\begin{array}{l}\text { Fundamental } \\
\text { incompleto }\end{array}$ & 18,3 & 19,0 & 22,5 & 20,9 & 11,5 & 13,4 & 14,1 & 13,4 \\
\hline & $\begin{array}{l}\text { Fundamental } \\
\text { completo }\end{array}$ & 24,2 & 24,0 & 285 & 26,7 & 19,0 & 19,3 & 24,7 & 22,4 \\
\hline & Médio completo & 42,6 & 40,5 & 36,3 & 38,6 & 53,0 & 52,0 & 47,5 & 49,6 \\
\hline & $\begin{array}{l}\text { Superior } \\
\text { completo }\end{array}$ & 14,6 & 16,3 & 12,2 & 13,4 & 16,4 & 15,1 & 13,4 & 14,4 \\
\hline & Total & 100,0 & 100,0 & 100,0 & 100,0 & 100,0 & 100,0 & 100,0 & 100,0 \\
\hline \multirow{5}{*}{$4^{\circ}$} & $\begin{array}{l}\text { Fundamental } \\
\text { incompleto }\end{array}$ & 19,8 & 19,5 & 26,0 & 23,9 & 11,4 & 12,7 & 15,3 & 14,1 \\
\hline & $\begin{array}{l}\text { Fundamental } \\
\text { completo }\end{array}$ & 24,2 & 25,2 & 32,1 & 29,6 & 17,1 & 18,3 & 25,9 & 23,0 \\
\hline & Médio completo & 48,8 & 48,3 & 36,0 & 40,2 & 61,3 & 60,1 & 50,6 & 54,2 \\
\hline & $\begin{array}{l}\text { Superior } \\
\text { completo }\end{array}$ & 7,1 & 6,9 & 5,5 & 6,0 & 10,1 & 8,8 & 8,1 & 8,6 \\
\hline & Total & 100,0 & 100,0 & 100,0 & 100,0 & 100,0 & 100,0 & 100,0 & 100,0 \\
\hline \multirow{5}{*}{$5^{\circ}$} & $\begin{array}{l}\text { Fundamental } \\
\text { incompleto }\end{array}$ & 36,3 & 39,7 & 44,1 & 42,1 & 26,6 & 31,3 & 31,3 & 30,5 \\
\hline & $\begin{array}{l}\text { Fundamental } \\
\text { completo }\end{array}$ & 29,9 & 31,5 & 35,2 & 33,7 & 25,2 & 25,9 & 34,2 & 31,5 \\
\hline & Médio completo & 30,6 & 26,0 & 18,0 & 21,4 & 44,5 & 39,8 & 32,6 & 35,6 \\
\hline & $\begin{array}{l}\text { Superior } \\
\text { completo }\end{array}$ & 1,0 & 1,0 & 0,7 & 0,8 & 2,3 & 1,1 & 0,7 & 1,0 \\
\hline & Total & 100,0 & 100,0 & 100,0 & 100,0 & 100,0 & 100,0 & 100,0 & 100,0 \\
\hline \multirow{5}{*}{ Total } & $\begin{array}{l}\text { Fundamental } \\
\text { incompleto }\end{array}$ & 27,0 & 29,5 & 35,3 & 32,7 & 18,5 & 22,0 & 24,1 & 22,7 \\
\hline & $\begin{array}{l}\text { Fundamental } \\
\text { completo }\end{array}$ & 26,6 & 27,6 & 32,4 & 30,5 & 21,4 & 22,1 & 30,0 & 27,7 \\
\hline & Médio completo & 37,0 & 33,4 & 25,4 & 29,0 & 49,1 & 46,3 & 38,8 & 41,9 \\
\hline & $\begin{array}{l}\text { Superior } \\
\text { completo }\end{array}$ & 8,2 & 8,4 & 5,5 & 6,5 & 10,3 & 8,5 & 6,3 & 7,4 \\
\hline & Total & 100,0 & 100,0 & 100,0 & 100,0 & 100,0 & 100,0 & 100,0 & 100,0 \\
\hline
\end{tabular}

Fonte: Elaboração própria com base em dados da RAIS (2003-2008). 
Tabela 7 - Relação entre os rendimentos médios dos ocupados formais em estabelecimentos industriais e o total da indústria, segundo grupamentos ocupacionais e condição de exportação no Brasil (2003-2008)

\begin{tabular}{|c|c|c|c|c|c|c|}
\hline & 2003 & 2004 & 2005 & 2006 & 2007 & 2008 \\
\hline \multicolumn{7}{|c|}{ Permanentes } \\
\hline $1^{\circ}$ & 12,6 & 13,0 & 13,7 & 12,6 & 13,9 & 13,2 \\
\hline $2^{\circ}$ & 3,3 & 3,3 & 3,3 & 3,2 & 3,3 & 3,2 \\
\hline $3^{\circ}$ & 1,7 & 1,7 & 1,7 & 1,7 & 1,6 & 1,6 \\
\hline $4^{\circ}$ & 1,5 & 1,5 & 1,5 & 1,5 & 1,5 & 1,5 \\
\hline $5^{\circ}$ & 0,9 & 0,9 & 0,9 & 0,9 & 0,9 & 0,9 \\
\hline Total & 1,3 & 1,4 & 1,4 & 1,3 & 1,3 & 1,4 \\
\hline \multicolumn{7}{|c|}{ Potenciais } \\
\hline $1^{\circ}$ & 11,3 & 11,3 & 11,4 & 11,5 & 11,8 & 11,1 \\
\hline $2^{\circ}$ & 3,0 & 3,4 & 3,1 & 2,9 & 2,9 & 2,8 \\
\hline $3^{\circ}$ & 1,6 & 1,7 & 1,6 & 1,5 & 1,5 & 1,4 \\
\hline $4^{\circ}$ & 1,3 & 1,3 & 1,3 & 1,3 & 1,3 & 1,3 \\
\hline $5^{\circ}$ & 0,7 & 0,7 & 0,7 & 0,7 & 0,7 & 0,7 \\
\hline Total & 1,2 & 1,2 & 1,1 & 1,1 & 1,2 & 1,1 \\
\hline \multicolumn{7}{|c|}{ Não exportadores } \\
\hline $1^{\circ}$ & 7,5 & 7,8 & 7,9 & 8,5 & 8,5 & 8,6 \\
\hline $2^{\circ}$ & 2,5 & 2,4 & 2,5 & 2,5 & 2,4 & 2,5 \\
\hline $3^{\circ}$ & 1,2 & 1,2 & 1,2 & 1,2 & 1,2 & 1,2 \\
\hline $4^{\circ}$ & 0,9 & 0,9 & 0,9 & 0,9 & 0,9 & 0,9 \\
\hline $5^{\circ}$ & 0,6 & 0,6 & 0,6 & 0,6 & 0,6 & 0,6 \\
\hline Total & 0,8 & 0,8 & 0,8 & 0,9 & 0,9 & 0,9 \\
\hline \multicolumn{7}{|c|}{ Total } \\
\hline $1^{\circ}$ & 9,4 & 9,8 & 10,0 & 10,0 & 10,3 & 10,0 \\
\hline $2^{\circ}$ & 2,7 & 2,8 & 2,8 & 2,7 & 2,7 & 2,7 \\
\hline $3^{\circ}$ & 1,4 & 1,4 & 1,4 & 1,4 & 1,4 & 1,4 \\
\hline $4^{\circ}$ & 1,0 & 1,1 & 1,1 & 1,0 & 1,0 & 1,1 \\
\hline $5^{\circ}$ & 0,6 & 0,6 & 0,6 & 0,6 & 0,7 & 0,6 \\
\hline Total & 1,0 & 1,0 & 1,0 & 1,0 & 1,0 & 1,0 \\
\hline
\end{tabular}

Fonte: Elaboração própria com base em dados da RAIS (2003-2008).

O que deve ser ressaltado é a significativa diferença salarial entre empregados de estabelecimentos exportadores e não exportadores. Isso implica afirmar que o crescimento econômico e a expansão da atividade industrial, que contribuíram para a ampliação do emprego formal, não se mostraram capazes de transformar estruturalmente o perfil ocupacional e salarial da indústria brasileira desse período.
Gráfico 2 - Índice de GINI para os salários dos trabalhadores da indústria segundo a condição de exportação no Brasil (2003-2008)

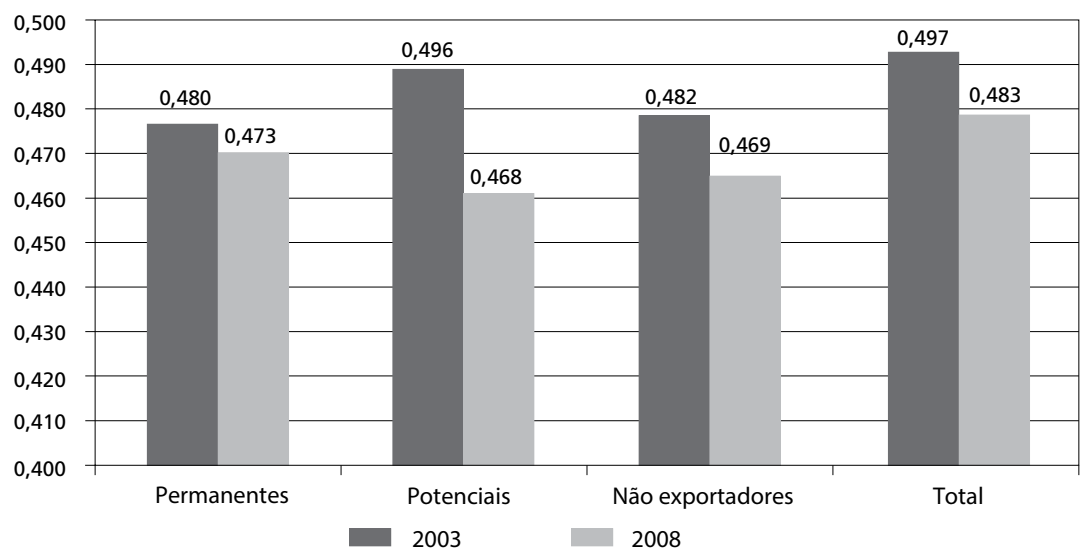

Fonte: Elaboração própria com base em dados da RAls (2003-2008).

\section{CONSIDERAÇÕES FINAIS}

Como apontado no início deste artigo, a recuperação da economia brasileira nos anos 2000 apresentou características não observadas em situações semelhantes conhecidas por ela anteriormente. Uma delas foi a maior inserção externa da estrutura produtiva, que explicou uma situação particular de formação de divisas de moeda estrangeira em volume considerável. É fundamental para a sustentação do crescimento observado até 2008, que a inserção externa seja mantida e ampliada, especialmente se consideradas as novas condições que caracterizam a divisão internacional do trabalho, marcadas fortemente pela crescente importância da economia chinesa, e pela instabilidade do padrão monetário internacional, imposta pela fragilidade e desvalorização do dólar.

$\mathrm{O}$ artigo procurou apresentar alguns indicativos sobre a contribuição das empresas com inserção externa para a geração de empregos e a qualidade da estrutura ocupacional no período de crescimento da atividade econômica e das exportações. É amplamente reconhecida que a indústria brasileira tem um perfil dominado por setores de menor produtividade, situação associada, ao menos parcialmente, a uma estrutura ocupacional dominada por emprego de baixa qualificação.

O crescimento da economia com maior inserção externa é capaz estimular mudanças positivas tanto na estrutura produtiva quanto na de emprego. Apesar do curto período analisado, existem sinais de que o crescimento dos anos 2000 mostrou virtuosidade para produzir mudanças positivas na estrutura de emprego de acordo com as 
características apontadas. Ademais, a retomada desse cenário pode produzir efeitos importantes para alterar a estrutura ocupacional no setor industrial brasileiro.

Deve-se considerar o desempenho das empresas exportadoras em alterar a estrutura ocupacional como um elemento potencial, pois os resultados apontam que as vantagens em termos de ocupação dessas empresas não se traduziram em mudanças estruturais no perfil do emprego industrial como um todo.

Ademais, mudanças desta natureza dependem tanto da maior inserção externa quanto do padrão de crescimento do mercado interno e seus impactos sobre a estrutura produtiva. Neste sentido, o potencial de qualificação da estrutura ocupacional encontra-se associado à ocorrência de transformações no desenvolvimento industrial, que se traduzem na elevação da densidade tecnológica da base produtiva. A elevação do perfil de qualificação da estrutura de emprego é parte integrante tanto de uma estratégia de elevação do valor agregado relativo da produção industrial, como para um rompimento do perfil de baixos salários ainda prevalecente no setor.

O crescimento dos anos 2000 mostrou não haver paradoxo entre expansão do mercado interno e crescimento das exportações para a geração de emprego. A retomada da atividade econômica, que se deu mais fortemente a partir de 2004, não se contrapôs à ampliação do volume das exportações nem à expressiva geração de emprego em estabelecimentos exportadores, que se mostraram mais favoráveis aos empregados industriais nesse período.

A estratégia da política industrial brasileira pode ser convergente com um crescimento com estas características, ao buscar elevar o perfil tecnológico da base produtiva de modo a reduzir a dependência externa e estimular maior inserção nos mercados internacionais, ao mesmo tempo em que se procura garantir a geração de empregos e a elevação do perfil de qualificação da estrutura de emprego.

No entanto, deve-se reconhecer que a crise internacional que se abateu sobre a economia mundial no final de 2008 parece se estender até o presente momento, sem sinais de recuperação para a economia mundial. As repercussões dessa crise para o cenário externo ainda são sentidas pelo Brasil. Parece haver muitas dificuldades em se encontrar um caminho correto para superar os obstáculos que impedem que a economia nacional retome o patamar de crescimento dos anos 2003-2008.

É relevante o aprofundamento e a atualização desse trabalho para o período subsequente a essa crise em um trabalho posterior. O objetivo seria entender quais foram os impactos que o baixo crescimento econômico do início da década de 2010 e a dificuldade observada no comércio externo carregaram para a estrutura de emprego na indústria nacional e para as empresas exportadoras.

Deve-se destacar que um caminho possível para a superação das dificuldades até o momento observadas e para a retomada do nível de crescimento econômico, observado no período 2003-2008, encontra-se no enfrentamento dos estrangulamentos de infraes- trutura que bloqueiam e causam transtornos para a competitividade das empresas nacionais, frente a concorrência internacional. Nesse sentido deve-se buscar uma combinação de incentivos promovidos pelo Estado de forma a fomentar e reaquecer a atividade econômica nacional buscando ampliar e fortalecer a capacidade de competição das empresas exportadoras, que por apresentar um perfil ocupacional diferenciado, pode trazer benefícios à parcela do mercado de trabalho associada ao setor industrial nacional.

Em síntese, são grandes os desafios que o processo encontra em termos de consolidação de um movimento mais sustentado e de longa duração, de forma a permitir a emergência tanto de uma estrutura produtiva mais qualificada quanto de uma estrutura de emprego com características menos desiguais. Políticas de apoio a maior inserção externa e de desenvolvimento tecnológico necessitam ser articuladas às políticas de educação e formação profissional de mão de obra. As bases para a realização destas iniciativas existem, portanto, é fundamental que o país estabeleça uma estratégia abrangente para que elas produzam os resultados desejados.

\section{REFERÊNCIAS}

ALDENDERFER, M. S.; BLASHFIELD, R. Cluster analysis. Quantitative Applications in the Social Sciences, v. 44, 1984.

BAILEY, K. “Cluster Analysis”. In: HEISE, D. R. (Ed.) Sociological Methodology. Vol. 6. San Francisco, CA: American Sociological Association, 1975, p. 59-128.

BUSSAB, W. O.; MIAZAKI, E. S.; ANDRADE, D. F. Introdução à análise de agrupamento. In: SIMPÓSIO NACIONAL DE PROBABILIDADE E ESTATÍSTICA, 9,1990. Anais. São Paulo: IME/USP, p. 105, 1990

DE NEGRI, F.; DE NEGRI, J. A.; COELHO, D. TURCHI, L. “Tecnologia, exportaç̃o e emprego". In: DE NEGRI, J. A.; DE NEGRI, F. COELHO, D. (Orgs.) Tecnologia, exportação e emprego. Brasília: IPEA, 2006, p. 533.

FEDERAÇÃO DAS INDÚSTRIAS DO ESTADO DE SÃO PAULO (FIESP). Desempenho das Exportações: até quando vai o crescimento? [On-line] FIESP, Departamento de Pesquisas e Estudos Econômicos (DEPECON), 20/09/2006. Disponível em: <http://www.fiesp.com.br/ economia/pdf/crescimento_exporta\%C3\%A7oes.pdf >. Acesso em: 28 out. 2014.

JAYME JR., F. G.; RESENDE, M. F. C. "Crescimento econômico e restrição externa: teoria e a experiência brasileira”. In: MICHEL, R.; CARVALHO, L. (Orgs.) Crescimento econômico: setor externo e inflação. Vol. 2. Rio de Janeiro: IPEA, 1999.

MARKWALD, R. E.; PUGA, F. Focando a política de promocão de exportações. Texto para Discussão, FUNCEX, n. 16, 2002. Disponível em: <http://www.bndespar.com.br/SiteBNDES/export/sites/default/bndes_pt/Galerias/Arquivos/conhecimento/livro_desafio/Relatorio-04.pdf >. Acesso em: 28 out. 2014 
MOREIRA, S. V.; MILHOMEM, E. E. L. Evolução recente do comércio exterior brasileiro com os países do Mercosul. Texto Para Discussão, IPEA, Rio de Janeiro, n. 1466, 2010.

PUGA, F. P. A inserção do Brasil no comércio mundial: o efeito China e potenciais de especialização das exportações. Textos para Discussão, BNDES, Rio de Janeiro, n. 106, out. 2005.

PUGA, F. P. Porque crescem as exportações brasileiras. Visão do desenvolvimento - BNDES, n. 1, 20 jun. 2006.

SABOIA, J. L. M.; CARVALHO, P. G. M. Produtividade na indústria brasileira - questões metodológicas e análise empírica. Texto para Discussão, IPEA, Brasília, n. 504, 1997.

SABOIA, J. M. Emprego industrial no Brasil: situação atual e perspectivas para o futuro. Revista de Economia Contemporânea, v. 5, especial, p. 207-229, 2001. Disponível em: <http://www. desenvolvimento.gov.br/arquivo/secex/sti/indbrasopodesafios/revecocontemporanea/art09JoaoSaboia.pdf>. Acesso em: 28 out. 2014.

VEIGA, P. M. "O viés anti-exportador: mais além da política comercial”. In: PINHEIRO, A. C.; MARKWALD, R.; PEREIRA, L. V. (Orgs.) O desafio das exportações. Rio de Janeiro: BNDES, 2002.

WARD, J. H. Jr. Hierarchical grouping to optimize an objective function. Journal of the American Statistical Association, n. 58, p. 236-244, 1963. 